\title{
Power games: Using Foucault to shed light on the inherent power dynamics of intercultural Bible study groups. Discussion of a qualitative research project
}

NGTT DEEL 55, NR 3 \& 4, 2014

\section{Van der Walt, Charlene}

Stellenbosch University

\section{ABSTRACT}

In theory the process of intercultural Bible reading should create a safe space where the voice of the individual can be heard in community with others. It should be a space where the individual is not only free to speak, but also to have the innate experience of truly being heard. In this respect the intercultural Bible reading experience becomes a space that promotes human dignity and has the inherent capacity to facilitate social transformation. Although these Bible study groups can ideally be a safe space with the potential for social transformation, the practical reality shows a more complicated dynamic. An important factor that contributes to the complexity is the underlying power dynamic in the social interaction. To bring the concept of power in intercultural Bible reading into focus, an empirical study was conducted. After briefly discussing the scope of the empirical research project, the main focus of the paper will shift to Michel Foucault's seminal theory on power. Conversation analysis was used in the research project as a qualitative data analysis tool to identify the main trends functioning in the observable power dynamic. Foucault's theory will be used to shed light on the inherent power dynamic that functions in the intercultural Bible reading space. The paper will show that the intercultural Bible reading space cannot escape the functioning of an inherent power dynamic, but by using Foucault's theory, a greater understanding can be obtained and observed trends and patterns can be better understood, predicted and managed.

\section{KEYWORDS}

Power, Michel Foucault, Intercultural Bible reading

\section{TREFWOORDE}

Krag, Michael Foucault, Interkulturele Bybellees

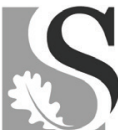




\section{CONTACT DETAILS}

Charlene van der Walt

Faculty of Theology, Stellenbosch University

Privaatsak X1, Matieland, Suid-Afrika, 7602

charlenevanderwalt@sun.ac.za

\section{NOTE}

Charlene van der Walt is currently serving as the Gender, Health, and Theology Master's Program Coordinator at the Department of Old and New Testament, Faculty of Theology, Stellenbosch University, South Africa. She also works as a researcher for Inclusive and Affirming Ministries (IAM) on a part-time basis and is an ordained Minister of Religion, serving as pastor to a congregation in Maitland, South Africa. Her book, Toward a Communal Reading of 2 Samuel 13:Power and Ideology within the Intercultural Bible Reading Process has recently been published (Intercultural Biblical Hermeneutics Series 2; Elkhart, IN: AMBS, 2014). 


\section{LEVELLING THE PLAYING FIELD}

The history of the interpretation of the Bible is a history of power and control. Jeremy Punt (2002:425) argues as follows: "Attempts to say what the Bible 'really means', to get the meaning, always stood in service of purposes determined by ecclesial, socio-political, ethical, nationalistic or other such concerns. Attempts to subvert existing claims to the Bible and its meaning often served similar, if opposing, interests. Although the very notion of the meaning of the biblical texts are denied by some today, it has to be acknowledged that many people continue to find the Bible a valuable guide for their lives. The Bible as site of struggle involves, however, more than difference of interpretive opinion. The Bible is involved in the discourse of power and is drawn into a struggle for interpretive control as well as eventually, ownership thereof." Looking back at the history of biblical scholarship it is clear that a privileged position of power was long held by the practitioners of Western academic scholarship. The language, themes of discussion and focus of investigation was mainly determined by the few who had access to the academic environment. This privileged position was challenged by Feminism and African hermeneutics by arguing for a different space of conversation and different conversation partners.

As challenge to the dominant approach of Western biblical scholarship the intercultural Bible reading space theoretically develops out of the combined hermeneutical framework of Feminism and African hermeneutics. Whereas Feminism argues for the importance of the contextually imbedded voice of the individual, African hermeneutics theoretically offers a communal space where the voice of the individual can be heard. The space that African hermeneutics describes, allows for the transformation from a situation of multiculturality to interculturality, where the differences between various cultural agents are not merely tolerated, but rather celebrated and where they are brought into real interaction. African hermeneutics thus asks for an ethic of hospitality.

The praxis of the intercultural Bible reading process therefore implies the coming together of diverse individuals from different cultural backgrounds within a safe space that allows for the equal opportunity interaction between these individuals and the culturally diverse Biblical text. By allowing for the interaction between culturally diverse individuals, the intercultural Bible reading process theoretically becomes a safe space that promotes human dignity and facilitates social transformation.

In order to test the above mentioned claims regarding the intercultural Bible reading space an empirical study was conducted in the local congregation where I served as pastor. The empirical study explored the complexities of the intercultural Bible reading space by examining aspects such as the inherent power dynamic that 
function in the space as well as the role that the ideological framework of individual participants played in the Bible reading process. ${ }^{1}$

The empirical Bible reading space and process that was constructed for the study brought together female Bible readers in Grahamstown, in the Eastern Cape province of South Africa. Four separate sessions took place with a group of eight culturally diverse woman ${ }^{2}$ taking part in each session. The sessions were planned and constructed in order to optimize the meeting between the culturally diverse women and to allow for enough time to engage with the culturally diverse Biblical text. The story of Tamar, as told in 2 Samuel 13:1-22, ${ }^{3}$ formed the basis for the intercultural

1 Although the physical empirical study examined both the complexities surrounding the inherent power dynamic as well as the influence of the ideological frameworks of the participants, this article will only discuss the process regarding the power dynamic analysis.

2 Cultural diversity was ensured in each group by the fact that participants were selected according to a structured profile. The profile was constructed in such a way as to represent the cultural diversity that exist in the Eastern Cape region. Each group consisted of a young person, a skilled reader, a reader for the Dutch Reformed community, someone representing the Anglican community, a Black/Xhosa speaking woman, a non-believer, a reader between the age of 30-40 years and a final participant that would enhance the group diversity in any way possible.

3 The choice for an Old Testament narrative text as the basis for a modern intercultural engagement was based on the following considerations: 1) The Bible is a well-known and often discussed piece of literature that functions in believing as well as nonbelieving communities. Participants would be able to engage with Biblical text from their unique reading positions whether believing or secular. 2) Narrative text is more approachable for modern readers, in the sense that readers approach characters in stories as they do people in everyday life. See Alter (1992:39) in this regard. 3) Stories are a unique tool for gaining insight and making sense of reality. Ackermann (2001:1819) explains this dimension of stories as follows: "Telling stories is intrinsic to claiming one's identity and in the process finding impulses for hope ... Narrative has a further function. Apart from claiming identity and naming the evil, narrative has a sensemaking function. The very act of telling the story is an act of making sense of an often incomprehensible situation, of a suffering and chaotic world in which people wrestle with understanding and in so doing seek to experience relief." 4) Feminism informs the choice of narrative in a number of ways: a) Because of the central focus on personal experience of Feminism, the text must tell of something that touches reader/hearer on an existential level. The story chosen for the research must thus invite modern readers/ hearers to engage with it from their own world of experience. b) The story of the rape of Tamar brings the venerable position of women in society into focus. Women in modern contexts are encouraged to engage with the text on this sensitive issue and break the silence. c) Feminism places emphasis on the body. In the story of Tamar's 
engagement and participants were lead through a process that allowed them to engage with the Biblical narrative on a deep level. The three-hour sessions, designed to obtain the qualitative ${ }^{4}$ empirical data, consisted of ten phases ${ }^{5}$ that slowly led the participants deeper into the intercultural engagement.

The data collected during the physical research process was reworked into a digital format in order to simplify the analysis thereof. After transcribing the recorded conversations, a detailed conversation analysis was conducted. The results of the conversation analysis formed the basis of the power analysis results that the study produced.

\section{GAME THEORY}

Conversation analysis was used as a qualitative data analysis tool because of the fact that it best suited the theory of power that the study subscribes to. Before continuing the discussion of the research project and explaining the analysis strategy applied to the data in order to gain a better understanding of the inherent power dynamic of the intercultural Bible reading process, I would like to offer a brief discussion of Foucault's theory on power, as it forms the underlying foundation of the power

rape, her body is central. Modern readers are thus encouraged to read and speak from a position of the body. d) The abuse of power and the influence on woman and children are emphasized in the choice of text. 5) Tamar appeals to a communal ethic when she says that: “... such a thing is not done in Israel." In African hermeneutics, which appeals to a communal ethic, and where the intercultural Bible reading process functions as the backbone, it seems important to hear the voice of someone let down by the community.

4 The aim of the empirical study regarding the power dynamic of the intercultural Bible reading process was to identify and analyse the inherent power structures that could be observed when individuals from various cultural backgrounds came into interaction with each other. Because of this focus of the study, I chose to apply a qualitative research design that is described by Babbie as follows: (2004:370) "The non-numerical examination and interpretation of observations for the purpose of discovering underlying meanings and patterns of relationships." I chose a qualitative research design because it is, as described by Marshall \& Rossman (2006:2), "intrigued by the complexity of social interactions expressed in daily life and by the meanings that the participants themselves attribute to these interactions. These interests take qualitative researchers into natural settings, rather than laboratories, and foster pragmatism in using multiple methods for exploring a topic".

5 For a detailed description of the research process please see: Van der Walt, Charlene. "Close encounters: creating a safe space for intercultural Bible reading - Part II: general." Scriptura: International Journal of Bible, Religion and Theology in Southern Africa 110 (2012): 282-292. 
component of the empirical study. Due to the mere scope and complexity of Foucault's work, it would be impossible for me to give a finite and all-encompassing account of it within the parameters of this article. I will, therefore, limit myself to a discussion of the main arguments in Foucault's work that are relevant for the analysis of power within a specific social environment.

Foucault's work can also not be limited to one discipline or field of research, but broadly speaking his academic endeavour was concerned with three traditional problems, namely: "(1) knowledge and how that knowledge relates individuals to truth; (2) power (the relationships individuals have with others on the basis of that knowledge); and (3) self, the way in which individuals come to understand and speak about themselves in relation to knowledge and power" (George, 2000:92). Archaeology is the term used to describe Foucault's initial approach to the engagement with above-mentioned questions. ${ }^{6}$ Smart (1985:48) describes this use of the term as follows: "Archaeology seeks to describe the archive, the term employed by Foucault to refer to 'the general system of the formation and transformation of statements existent at a given period within a particular society." The goal of this strategy of discourse analysis is not so much to trace the beginning and development of a certain discourse, but rather to document its conditions of existence and the practical field in which it is deployed. Foucault's archaeology focuses on the circumstances that make a certain discourse possible and the perceivable circumstances that maintain it as a reality. The effect of Foucault's approach is a conception of discourse as a diverse hybrid rather than a universal singular movement that takes the possibility of change seriously.

Although Archaeology as method of analysis always remained present in Foucault's work, it retained a secondary position in his later works next to the more prominent mode of analysis, namely genealogy. Central to genealogy as an approach is: "a conception of historical analysis which stands in opposition to a pursuit of the origin of things on the grounds that such a search inevitably induces particular effects, namely an attempt to 'capture the essence of things'; a tendency to regard the moment of origin as the high point of a process of development; and finally an associated constitution of a field of knowledge emanating from an assumed origin which itself is to be retrieved" (Smart, 1985:56). In contrast, Foucault's Genealogy shows "a disparity and dispersion behind the constructed identity of

6 Illustrations of this approach can be found in Foucault's early work, namely: Madness and Civilization (1961), The Birth of the Clinic: An Archaeology of Medical Perception (1963), The Order of Things: The Archaeology of the Human Sciences (1966) and The Archaeology of Knowledge (1969). 
origin; it shows historical beginnings to be lowly, and beneath 'measured truth, it posits the ancient proliferation of errors" (Smart, 1985:56). Genealogy thus rejects a conception of history as an uninterrupted stable flow of events, but rather recognizes the complexity of historical realities. Historical events are therefore not seen as a culmination of a process of development, but rather "a particular momentary manifestation of 'the hazardous play of dominations' or a stage of struggle between forces" (Smart, 1985:57). As a result, Smart (1985:57) remarks: "Genealogy embraces the confrontations, the conflicts, and the systems of subjection of which emergent historical forms are but temporary manifestation, furthermore within the scheme of things there is no place for a constituting subject, for 'no one is responsible for an emergence, it is merely an effect of the play of dominations." Foucault (1980a:117) describes this mode of historical analysis as follows: "And this is what I would call genealogy, that is a form of history which can account for the constitution of knowledge, discourses, domains of objects, etc., without having to make reference to a subject which is either transcendental in relation to the field of events or runs in its empty sameness throughout the course of history." An important consequence of this method of historical analysis is the alternative understanding of knowledge that it brings about. ${ }^{7}$ Foucault defines the power-knowledge relationship as follows: "Knowledge is inextricably entwined with relations of power and advances in knowledge are associated with advances and developments in power are mutually and inextricably interdependent. A site where power is exercised is also a place at which knowledge is produced" (Smart, 1985:64). According to Foucault, power and knowledge necessarily function together; knowledge is made possible through power and power is effective due to knowledge. Genealogy as a method of analysis is designed "to excavate patterns of power: not who has power, but rather the patterns of the exercise of power. Foucault's genealogy was a method and project, which rejected the search for origins and took as its object and subject the relations between knowledge and power: The exercise of power perpetually creates knowledge and, conversely, knowledge constantly induces effects of power. In fact, the fused appellation power/knowledge is now associated with Foucault" (McNeil, 1993:149). Foucault very effectively illustrates this method of analysis in his later works, especially: Discipline and Punishment in 1975 and The history of sexuality that appeared in three volumes between 1976 and 1984.

7 "Knowledge" as used by Foucault stands in contrast to the traditional concept of "scientific knowledge". Smart (1985:62) remarks on this distinction as follows: "Genealogy as critique stands in opposition to the scientific hierarchization of knowledge about human beings and social relations and the effects intrinsic to their associated technologies of power" (Smart 1985:62). 
By rigorously applying both archaeology and genealogy as methods of historical analysis, Foucault developed a comprehensive theory on power. Foucault holds that "one should never try to understand power divorced from the context in which it shows itself" (Flaskas \& Humphreys, 1993:40). Power is relational ${ }^{8}$ and has the potential for functioning in a positive manner. ${ }^{9}$ Thus as George (2000:92) remarks: "When Foucault discusses power, he does not mean by this idea a fixed quantitative, or physical force, something innately possessed or held by individuals or institutions. He acknowledges that power often is channelled through people or institutions, but this is not due to the inherent 'power' of such people or institutions. Rather, Foucault understands power as a force, something present throughout the world and in all people. Power is therefore something distinct from authority. Everyone has power, whether they exercise that power individually, in groups or through institutions."

According to Foucault, power functions within relational frameworks in such a manner as to always attain more power. George (2000:93) describes this strategic functioning of power as follows: "Power, whether individual or institutional, always seeks to become more powerful and influential in society, and thus there is constant interaction, negotiation, and competition among forces. Frequently, forces combine in particular, complex arrangement or configuration in order to achieve more power." Because of the complex combination and developments in the construction process of power relations, social institutions such as banks, the police, medical institutions and professional organisations often exert power. Notwithstanding Foucault claims that power is not inherent to these organisations but is a result of complex circumstances and historical realities. Change in the conducive circumstances for certain power dynamics is due to the implicit functioning of resistance. Foucault (1980b:142) claims where there is power, there is resistance: ${ }^{10}$ "There are no relations of power without resistances; that the latter are all the more real and effective to

8 Flaskas \& Humphreys (1993:40) comments on this notion of Foucault as follows: "The concept of power is an epistemological error, one individual cannot hold unilateral power over another, because people are always subject to the constraints of relationships."

9 Power as concept is often viewed in a negative light due to the misuse of power by corrupt authorities, but Foucault (1980a:119) remarks: "If power were never anything but repressive, if it never did anything but to say no, do you really think one would be brought to obey it? What makes power hold good, what makes it accepted, is simply that fact that it doesn't only weigh on us as a force that says no, but that it traverses and produces things, it induces pressure, forms of knowledge, produces discourse. It needs to be considered as a productive network, which runs through the whole social body, much more than as a negative instance whose function is repression."

10 Smart (1985:77) concludes about the reality of resistance by saying: "Where there is power there is resistance, that power depends for its existence on the presence of a 
the extent that they are formed there where the relations of power are exercised resistance to power doesn't have to come from elsewhere in order to be real, nor is it trapped because it is the compatriot of power. It exist all the more insofar as it is there where power is; it is therefore like power, multiple and integrable into global strategies."

Foucault (1980b:142) summarises his theory on power as follows: "It seems to me that power is 'always already there' that one is never 'outside' it ... I would suggest (i) that power is co-extensive with the social body; there are no spaces of primal liberty between the meshes of its network; (ii) that relations of power are interwoven with other kinds of relations (production, kinship, family, sexuality) for which they play at once a conditioning and a conditioned role; (iii) that these relations don't take the sole form of prohibition and punishment, but are of multiple forms; (iv) that their interconnections delineate general conditions of domination, and this domination is organised into a more-or-less coherent and unitary strategic form; that dispersed, heteromorphic, localised procedures of power are adapted, reenforced and transformed by these global strategies, all this being accompanied by numerous phenomena of inertia, displacement and resistance; hence one should not assume a massive and primal condition of domination, a binary structure with 'dominators' on the one side and 'dominated' on the other, but rather a multiform production of relations of domination which are partially susceptible of integration into overall strategies; (v) that power relations do indeed 'serve', but not all because they are 'in service of' an economic interest taken as primary, rather because they are capable of being utilised in strategies; (vi) that there are no relations of power without resistances, that the latter are all the more real and effective because they are formed right at the point where relations of power are exercised ..."

Foucault's relational and contextual theory on power, that takes seriously the realities of resistance, its positive potential and its indissoluble relationship to knowledge was used to shed light on the complex power dynamic inherent to the contextual Bible reading process.

\section{MATCH ANALYSIS}

\subsection{Conversation analysis as research tool}

It is clear from Foucault's theoretical engagement with the concept of power that it is not a commodity that some own whilst others don't. According to Foucault, power

multiplicity of points of resistance and that the plurality of resistance should not be reduced to a single locus of revolt or rebellion." 
operates within a specific social reality and strategically functions in a relational manner in order to gain more power. To the contrary of what is often perceived in reality, power can also function in a positive way, and where power exists, there is always the possibility of resistance. Finally, because power and knowledge function so closely together, Foucault uses the term power/knowledge in his oeuvre. To study power implies a social context and a network of relationships that functions within the specific social context. Power is also not situated in one component of a social network, but rather functions in a complex interaction between different interdependent social entities.

The specific social reality that was examined in this study consisted of the four intercultural Bible reading sessions conducted in order to gain qualitative data. The relational character of these sessions was best illustrated in the conversations that took place in each of the groups. The conversations were not structured or manipulated by the research team in any way. After opening the conversation with a simple question ${ }^{11}$ each conversation developed uniquely according to the contributions of the participants. In order to identify and analyse the complex power dynamic that functions within the intercultural Bible reading process, an instrument of analysis was required that would do justice to the dynamic nature of conversation and the power implications of utterances within a conversation. Power within the intercultural Bible reading space does not reside with the individual and the goal of the analysis is not to identify the most powerful individual, ${ }^{12}$ but rather to analyse the social dynamic that functions within the conversation space. The tool that best suited the above-mentioned requirements was one that developed within the framework of qualitative data analysis, namely conversation analysis.

Laddicoat (2007:2) describes the research tool as follows: "Conversation analysis is an approach to the study of talk in interaction which grew out of the ethnomethodological tradition in sociology developed by Harold Garfinkle (1964, 1967,1988). Ethnomethodology as a field of sociology studies the common sense resources, practices and procedures through which members of a society produce and recognize mutually intelligible objects, events and courses of action." Laddicoat (2007:2) continues describing the focus of Garfinkle's ${ }^{13}$ work: "to study

11 Each conversation session started with the question: "What struck you most in your reading of the story of Tamar?" The conversation developed naturally as participants engaged with the question and responded on remarks from other participants.

12 A single most powerful individual is an impossibility according to the power theory of Foucault.

13 In more recent terms the development of conversation analysis as discipline can be linked to the name of Erving Goffman from Berkeley University in California and the 
the social structure of everyday lived experience and to develop an understanding of how structures of everyday activities are ordinarily and routinely produces and maintained." It is precisely because of the above-mentioned focus on the social dynamic that conversation analysis presented itself as the ideal tool to analyse the power dynamic within the intercultural Bible reading process.

Laddicoat describes the main points of departure for conversation analysis (2007:5) as follows:

1. "Order is produced orderliness. That is, order does not occur of its own accord nor does it pre-exist the interaction, but rather the result of the coordinated practices of the participant who achieve orderliness and then interact.

2. Order is produced, situated and occasioned. That is, the participants themselves produce order for the conversation in which it occurs. The participants themselves orient to the order being produced and their behaviour reflects and indexes that order.

3. Order is repeatable and recurrent. The patterns of orderliness found in conversation are repeated, not only in the talk of an individual speaker, but across groups of speakers."

The aim of conversation analysis is thus to analyse the order that functions within a conversation. ${ }^{14}$ Order is not a preconceived grid or idea that can be applied to a conversation, but develops spontaneously within a conversation and can thus be observed and described. ${ }^{15}$ Laddicoat (2007:5) explains the importance of order as

work done by his students namely, Harvey Sacks, Emmanuel A. Schegloff and Gail Jefferson. Sacks developed two themes quite extensively, namely: "categorization and sequential organization. The first followed from Sacks' previous interests in practical reasoning and was not essentially bound up with these materials as interactional. The second, however, was in essence 'new' and specific to talk-in-interaction as such. It can best be summarized briefly as the idea that what a doing, such as an utterance, means practically, the action it actually performs, depends on its sequential position. It was this 'discovery', which led to conversation analysis per se," (Ten Have, 1999:6).

14 Conversation analysis is always contextual. Laddicoat (2007:7) describes it as follows: "Talk is context-shaped in that talk responds to the context in which it is created. What participants say is shaped by and for the context in which it occurs and each next bit of talk is understood in the light of what has preceded it ... At the same time talk is context-renewing because talk shapes the context as each next bit of talk constrains and effects what follows and influences how further talk will be heard and understood."

15 Laddicoat (2007:11) describes the analytical task of conversation analysis as follows: "The analytical approach is an inductive one which seeks to build an understanding of regularities in the way talk is organized from the study of actual instances of interaction. 
follows: "It is clear that conversation analysis assumes that there is overwhelming order in conversation. Conversation is neither random nor unstructured; however, the order observable in conversation does not imply an overarching uniformity in conversational structure that is generalizable across conversation. Instead the participants themselves construct conversation in orderly ways" (Liddicoat, 2007: $5)$.

The goal of conversation analysis is to analyse naturally occurring talk. If such talk is to be used for detailed analysis, it must first be recorded and transcribed in order to find patterns in conversation and then to attempt to describe the logic of the conversation.

Ten Have (1999:110-119) recommends three strategies to the analysis of conversation:

a. "Turn taking organisation: The idea of turn taking as an organized activity is one of the core ideas of conversation analysis. As Sacks has observed, the basic fact about conversation is that, overwhelmingly, there is one and only one person speaking at a time, while speaker change recurs with minimal gap and minimal overlap." Speakers thus succeed each other in an almost organic fashion. Succession between speakers is achieved in one of three ways: "(A) next speaker can be selected by the previous one, a speaker can self-select, or the present speaker can continue speaking" (Ten Have, 1999:112). Laddicoat (2007:69-72) describes the work of Sacks et al on succession in greater detail. In conclusion, he remarks the following: "(i) Speaker change recurs, or at least occurs, (ii) One person talks at a time and occurrences of more than one speaker at a time are common but brief, (iii) Transition with no gap or no overlap are common, (iv) Turn order varies and the relative distribution of turns is not specified in advance, (v) Turn size is not fixed, but varies, (vi) Numbers of parties can vary, (vii) Talk can be continuous or discontinuous."

b. "Sequence organization: Utterances in interactional talk are sequentially organized. The idea of 'sequence' refers to the common experience that one thing can lead to another. For conversation, this means that any utterance in interaction is considered to have been produced for the place in the progression of the talk where it occurs, especially just after the preceding one, while at the same time it creates a context for its own next utterance." As a result of this type of analysis, one can construct a thematic analysis of a

The analyst, however, does not stop at a description of regularities, but rather is required to show that regularities are methodically produced and orientated by participants." 
conversation; seeing that a theme in conversation is often developed as one person links their utterance to that which preceded it.

c. "Repair organization: organized ways of dealing with various kinds of trouble in the interaction's progress, such as problems of (mis)hearing or understanding."

Once general trends and themes are identified, conversation analysis continues by bringing into focus specific trends and themes pertaining to the specific research question put to the data. There is no correct or absolute way to engage with conversation using the tools of conversation analysis. The goal is rather to engage with data in a creative and playful manner so as to find patterns, themes and trends.

\subsection{Applying conversation analysis}

The physical research groups that were constructed for the aim of intercultural Bible reading met on 23 and 30 May 2009. The data collected in the workbooks and the audio recordings of the conversations that took place in each group served as the raw data for the analysis process. The raw data was reworked into digital format in order to simplify the process of analysis.

I transcribed ${ }^{16}$ the conversations myself, convinced by the argument of Ten Have (1999:77). “Therefore, it is generally recommended that an analyst makes his or her own transcriptions. Even if the work is tedious, and just because it is tedious, it gives one a kind of access to the 'lived reality' of the interaction that is not available in any other way. In other words, because, for making a transcription, a researcher is forced to attend to details of the interaction that would escape the ordinary listener, transcription works as a major noticing device." The transcribed verbatim conversation served as the raw data for the analysis process.

The conversations were analysed using three different strategies that each focused on a particular aspect of the conversational dynamic.

\subsubsection{Turn taking analysis}

The results of the turn taking analysis were made intelligible by reflecting the content of the conversation in a table consisting of three columns.

16 It is important to keep in mind that according to the theoretical viewpoint of conversation analysis, transcribed conversation is second data. The transcribed conversations can never fully account for the richness of the physical conversation, as so much is lost in transcription. Transcribed conversations can accordingly not convey body language, mannerisms, nuances and the complexities of loaded emotional responses between participants. 
a. The verbatim transcription of the conversation was captured in the first column. The coding of the verbatim conversation was done using the following system:

\begin{tabular}{|l|l|}
\hline Colour & Symbol \\
\hline Text & Emotional response \\
\hline Text & Personal story/experience \\
\hline Text & Remark relating to Biblical story \\
\hline Text & Explicit reference to other participant \\
\hline
\end{tabular}

b. The second column captured analytical remarks pertaining to the specific utterances of the participants. Firstly, the number of words used in the utterance is indicated, followed by analytical remarks on the content of the utterance. The column also contains information on how remarks follow on each other, where applicable.

c. In the third column the themes coming to the fore in each individual utterance is indicated.

\subsubsection{Mechanic analysis ${ }^{17}$}

The mechanical analysis indicates how involved participants got in the conversation in terms of the amount of time that participants took up in the conversation as well as how often they participated in the conversation.

\subsubsection{Thematic analysis}

Using flow charts as a visual aid, the thematic analysis represented the development of themes in the conversation. According to the principles of conversation analysis, participants do not only succeed each other in turn taking, but also link to previous speakers thematically. The goal of the flow charts was to give a visual representation of the thematic flow of the conversation. Each new theme in the conversation was represented in the chart by indicating the person who introduced the theme and all those who contributed to the development of the theme in the conversation.

\section{GAME. SET. MATCH.}

The main question posed to the qualitative data collected during the empirical research sessions and analysed using conversation analysis as tool focused on the

17 The mechanical analysis connected the results of the ideological research question with that of the conversation analysis. Due to the fact that it is not part of the scope of this article, I will not discuss it in detail, but only remark on the relevant information for the power dynamic analysis. 
issue of the observable power dynamic that could be identified and interpreted within the intercultural Bible reading space. Although noticeable patterns developed, as will be indicated in the discussion below, it is important to note right at the outset that it is impossible to make any grand general statements regarding the inherent power dynamics of intercultural Bible reading groups. The main reason for this assertion is grounded in the fundamental theoretical viewpoint on power dynamics, as described by Foucault, that power is a relational strategy within a particular social context. No discussion of power is thus possible divorced from the specific social context in which it functions. Each group's power dynamic is unique and developed due to the interaction between the individual participants that took part in the group discussion.

I will now continue with a general discussion of the research results of the power dynamic analysis using the theory of Foucault as the framework for the discussion. I will illustrate how his theory helps one to unmask and understand the seemingly natural power dynamic that functions in the group discussions. I will illustrate the general trends that can be identified with examples from the empirical data. Four categories, deducted from Foucault's theory on power, will be used to discuss the empirical data, namely:

a. Power is relational and situated within a specific social context: Each intercultural Bible reading engagement is seen as a unique social occasion and the noticeable power dynamic is explored in this section. Dominant participants are identified and described within the confines of the specific social location. Reasons why some flourish and others wither within the specific social setup of intercultural Bible reading are explored.

b. Power/knowledge: The influence of unique or specialised knowledge that participants bring to the conversation is discussed.

c. Where there is power, there is resistance: The strategies of resistance are explored.

d. Positive implications of power: The positive implications of the functioning of a power dynamic within the groups are discussed.

\subsection{Power is relational and situated within a specific social context}

The conversation in each group developed in a unique way according to the way that the specific participants in each group interacted with each other. Although the criteria for the four different research groups were constantly the same, variables 
such as personality, communication style and religious frame of reference had a radical influence.

Dominance in the conversation was often not attained by individuals, but by alliances that developed between participants. In the first research group an alliance developed between four participants who shared a common demographic background and a similar style of communication. These four individuals dominated the central part of the conversation as common themes resonated between them and a reciprocal dynamic developed. The central part of the conversation was bracketed by the insights of an individual participant who shared her expert cultural views with the group. Her dominance in the conversation can be ascribed to the fact that she had important insights within the Xhosa culture because of her position within the cultural and religious community. In the second research group a virtual dialogue within the conversation developed between two individuals who shared a very similar demographic. The dialogue developed because the theme of the conversation was kept within the parameters of the knowledge scheme that the two participants shared. One of the dialogue partners was a very influential social leader within the community whilst the other was a skilled reader. The conversation within the conversation thus developed around skilled knowledge of the community and the biblical text. In the third and fourth conversation a broad spectrum of participants contributed to the conversation due to the fact that the content of the discussion remained in the social sphere. Because every participant had her own experience of social realities, these empowered individuals to partake in the conversation.

Dominance within a conversation was thus attained by individuals/alliances due to their expert knowledge of a particular cultural system, biblical tradition or conversation method and because of a shared demographical reality. Alliances developed in line with Foucault's theory that power always functions strategically in order to gain more power. Individuals with expert knowledge often linked to other skilled individuals to form an alliance.

\subsection{Power/knowledge}

Foucault does not distinguish between power and knowledge as two separate concepts, but rather uses the term power/knowledge. Participants who had skilled knowledge of their social reality, the Biblical text or the style of conversation were often the more dominant and therefore prone to powerful alliances. In the second conversation the alliance that developed between two very skilled individuals, one socially, the other biblically, were exclusive in nature. In the third and fourth conversation the communal experiential knowledge of the social reality were inclusive as all participants could share from their own experience. 
The presence of skilled readers in each group had an interesting influence on the group dynamic. The role of the skilled reader in the intercultural Bible reading process is a heavily debated on $\mathrm{e}^{18}$ and I therefore chose to include a skilled reader in each of the research groups. The influence that the skilled reader had on the research group again has to be considered within the social context of the specific group. From the data analysed for this study, it can be concluded that skilled readers impacted on the conversation in one of two ways.

Firstly it seems that the skilled reader can determine the direction of the conversation by using power/knowledge in an exclusive manner. Hereby the conversation stays within the framework of specialised biblical knowledge and less skilled readers are therefore excluded. One of the skilled readers commented on her experience of the process by stating: "I struggled not to dominate the discourse with my own knowledge and opinions. I wanted to take up so many more issues than I did - and I did speak a lot anyway. I find myself dominating and wanting to argue."

A second approach can be described as more inclusive, whereby the skilled reader uses their specialised knowledge to illuminate the text and explain difficult issues in order to enrich the discussion. This second approach not only enriches the discussion, but also allows for a broader base of participants. The approach skilled readers take depends on their attitude towards the conversation process. Skilled readers invested in the group dynamic and the development of themes important to the group, using their expertise knowledge to stimulate further conversation. One of the skilled readers in the fourth research group felt partly responsible for a positive group dynamic. She describes the power that functioned in the conversation as

18 West (2007:2), as a main role player in this debate, states: "Part of the substantive claim I am making in differentiating between the scholar and non-scholar/ordinary reader is that there is a difference in the way each of these sectors read biblical texts. This difference is significant, and recognition of this difference can lead to creative and socially transformative collaboration between different sets of interpretive resources these different sectors bring to a collaborative reading project. So, in the general sense of 'ordinary reader', I am focusing on the kind of interpretive training different sectors have received. The ordinary reader has been 'trained' by his or her primary (for example, the family) and secondary (for example, the church and school) communities, whereas the scholarly reader has been trained by a tertiary community, the academy." A complex power dynamic can be expected, because of the different positions from which ordinary and scholarly readers read the Bible. Anum (2007:14) remarks in this regard: "There is the factor of power relationships that cannot be overlooked in this venture of ordinary and scholarly readers reading together." By including a skilled reader in each research group, the study further explored the power dynamic as alluded to by Anum (2007:14). 
follows: "Not so much power 'over' but power 'along with' others. Together we experienced different responses to the text." It can therefore be concluded that the presence of skilled readers in the intercultural Bible reading process can be of great value, but it depends on the skilled reader's attitude towards the conversation process and their indebtedness in the group dynamic. That skilled readers can enrich the conversation and include other participants by using their skills cannot be negated, but the attitude of the skilled reader is of utmost importance.

\subsection{Where there is power, there is resistance}

Initially in the construction of the research process I equated resistance with confrontation. I assumed that resistance would take on the character of heated arguments or emotional discussions. To my surprise, that was not the strategy of resistance that could be identified in the conversations. There were virtually no outright confrontations, but participants would show resistance by withdrawing from the conversation. Silence became the strongest strategy of resistance. It is probably best illustrated in the third research group where one participant completely withdrew from the conversation by not contributing once. In her reflection on the experienced power dynamic in the group she remarks: "Feeling of powerlessness: Yes, as someone with a more impersonal and academic interest in the text, it didn't seem appropriate to change the direction of the discussion away from current personal and social stories." The power/knowledge base of the third conversation functioned around social realities. Although the above-mentioned participant is an extremely skilled and well-educated individual, she did not fit the power/knowledge profile of the group. In the first research group, another participant also showed resistance in silence, not due to the power/knowledge configuration, but rather the lack of social identification. She described her experience as follows: "Feeling of powerlessness: Yes, it is my first day to attend and I feel empty sometimes." In terms of the demographic of the group she was the most alternative individual and there were no obvious alliance partners for her in the group.

In the first research group an interesting dynamic developed after an individual participant shared a rather longwinded, very emotional story about her experience of injustice in society. It is clear that the group felt that the story was inappropriate and that it hijacked the conversation. From the theme analysis of the conversation it is clear that no utterance latched on to the story and that the theme did not develop any further. By not taking up the theme, the group showed communal resistance. 
Each conversation developed uniquely and the power dynamic that functioned within the conversation can largely be described by analysing the dynamic between the specific participants in each group. Although power is often equated with something negative, it functioned in a positive way in the intercultural Bible reading space in a number of ways. Firstly, the conversations often reflected the communal realities faced by participants in society. Secondly, the women felt a greater sense of solidarity after the intercultural conversations. Finally, the conversations gave rise to a feeling of hope, because most of the participants felt heard and encouraged by the others.

\section{CONCLUDING REMARKS}

It is clear, therefore, that the intercultural Bible reading space cannot avoid the functioning of an inherent power dynamic. Power functions in all social contexts and the development of alliances are unavoidable. Alliances mainly develop between individuals due to a shared understanding, experience or frame of reference. Participants who get involved in alliances very often have the experience of being heard or understood and this allows them to partake more freely in the group dynamic. Individuals excluded from alliances often feel isolated and will therefore frequently employ a strategy of resistance. Resistance does not always imply confrontation, but is most visible in the data analysis when participants withdraw from the conversation and employ a strategy of silence.

In the construction of intercultural groups it is therefore important to not only consider diversity as criteria for group composition, but also communality, as this is the main factor that contributes to the formation of alliances and resulting power dynamics. Radically different individuals often lose their voice as their experience does not resonate with the rest of the group and this leads to isolation.

As also argued elsewhere, it is clear that the intercultural Bible reading space is one that holds the possibility for social transformation and the development of human dignity, but it has to be treated as a complex space that has to be carefully constructed and managed.

\section{BIBLIOGRAPHY}

Ackermann, DM 2001. Tamar's cry: Re-reading an ancient text in the midst of an HIV/AIDS pandemic. Johannesburg: Ecumenical Foundation of Southern Africa.

Alter, R 1992. The world of Biblical literature. New York: Basic Books. 
Anum, E 2007. Ye ma wo mo! African hermeneuts, you have spoken at last: reflections on Semeia 73. In Reading otherwise: socially engaged biblical scholars reading with their local communities. Atlanta: SBL. 7-18.

Babbie, E 2004. The practice of social research. $10^{\text {th }}$ edition. New York: Wadsworth Publishing Company.

Flaskas, C \& Humphreys, C 1993. Theorizing about power: Intersecting the ideas of Foucault with the 'problem' of power in family therapy. Family Process, 32(1):35-47.

Foucault, M 1980a. Truth and power, in Gordon, C (ed). Power/knowledge: Selected interviews and other writings. 1972-1977. Sussex: The Harvest Press. 109-133.

Foucault, M 1980b. Power and strategies, in Gordon, C (ed). Power/knowledge: Selected interviews and other writings. 1972-1977. Sussex: The Harvest Press. 134-145.

George, MK 2000. Foucault, in Adam, A.K.M. (ed). Handbook of postmodern Biblical interpretation. Missouri: Chalice Press. 91-98.

Liddicoat, AJ 2007. An introduction to conversation analysis. London: Continuum.

Marshall, C \& Rossman, GB 2006. Designing qualitative research. London: Sage Publications

McNeil, M 1993. Dancing with Foucault: Feminism and power-knowledge. In Ramazanoğlu, C (ed), Up against Foucault: Explorations of some tensions between Foucault and feminism. London: Routledge. 147-179.

Punt, J 2002. From re-writing to re-reading the Bible in post-colonial Africa: Considering the options and implications. Missionalia, 30(3):410-442.

Sheridan, A 1980. Michel Foucault: The will to truth. London: Tavistock Publications.

Smart, B 1985. Michel Foucault. London: Travistock Publications.

Ten Have, P 1999. Doing conversation analysis: A practical guide. London: Sage Publication.

West, GO 2007. Introduction. In Reading otherwise: socially engaged biblical scholars reading with their local communities. Atlanta: SBL. 1-6. 